\title{
O DIREITO FUNDAMENTAL SOCIAL À SAÚDE E A ADMINISTRAÇÃO PÚBLICA
}

\section{THE RIGHT TO HEALTH AND SOCIAL FUNDAMENTAL PUBLIC ADMINISTRATION}

\section{Adriana da Costa Ricardo SCHIER ${ }^{1}$ Léa Maria Massignan BEREJUK ${ }^{2}$}

Artigo recebido em: 11/07/2016

Artigo aprovado em: 31/08/2016

RESUMO: Este estudo tem por objetivo analisar o direito fundamental social à saúde como dever do Estado na prestação de bem estar e promoção da dignidade da pessoa humana. A partir de um breve resgate histórico, observouse a evolução do Estado Liberal para o Estado Social e o consequente surgimento dos direitos sociais, recepcionados pela Constituição Federal de 1988, que impôs à Administração Pública o dever de promover e realizar serviços públicos voltados à prestação de bens essenciais, que assegurem ao cidadão a realização dos direitos fundamentais de dimensão prestacional, como processo de concretização da dignidade da pessoa humana.

\footnotetext{
${ }^{1}$ Doutora em Direito pela Universidade Federal do Paraná. Pós-Doutoranda em Direito no Programa de Pós Graduação da Pontifícia Universidade Católica do Paraná. Professora do Programa do Mestrado do Centro Universitário Autônomo do Brasil, Unibrasil. E-mail: adrianacrschier@uol.com.br
${ }^{2}$ Mestranda do programa de mestrado do Centro Universitário Autônomo do Brasil, Unibrasil - área de concentração "Direitos Fundamentais e Democracia".
E-mail: leaberejuk@yahoo.com.br


PALAVRAS-CHAVE: direito fundamental social; saúde; dignidade humana; administração pública.

ABSTRACT: This study aims to analyze the fundamental social right to health as a duty of the state in providing welfare and promoting human dignity. From a brief historical review, there was the evolution of the liberal state to the welfare state and the consequent emergence of social rights, delivered by the Constitution of 1988, which imposed the Public Administration the duty to promote and carry out public services focused on the provision of essential goods that ensure citizens its fundamental rights as of being supplied as a process of human dignity.

KEY WORDS: fundamental social right; health; human dignity; public administration. 


\section{Introdução}

A fragilidade do ser humano se revela em aspectos morais, físicos e psicológicos e induz a pensar na necessidade de proteção para a sua existência, de modo a garantir a continuidade da espécie. Dada essa condição humana, certo é que qualquer pessoa está vulnerável a todo tipo de interferência, razão pela qual necessita de atenção e cuidados. No entanto, a realidade mostra a todo instante que essa fragilidade se acentua aos que têm menores condições materiais para se manter.

Dentre as possíveis fragilidades que representam ameaça à existência, destacam-se primordialmente os danos à saúde, e, considerando-se que saúde é o bem que resguarda o maior de todos os bens, o bem da vida, eleva-se à categoria de um direito fundamental, e, portanto, um bem que necessita de proteção pelo Poder Público.

Ainda que já se tenha escrito exaustivamente a respeito desse tema e de suas implicações para o Poder Público, constata-se que o assunto ainda está longe de ser esgotado, uma vez que as deficiências observadas são significativas e o atendimento está muito aquém de atingir um patamar ideal. Portanto, relevante repensar a atuação da Administração Pública nessa seara, sendo essa a razão que motiva o estudo do direito fundamental social à saúde, nos termos consagrados pela Carta Magna.

Partindo do pressuposto do direito constitucional à saúde como forma de consolidação dos valores do Estado Democrático de Direito, e, considerando que não basta apenas uma declaração formal de intenções materializadas em instrumentos normativos para a sua realização, este estudo tem a pretensão de contribuir na reflexão sobre a saúde como instrumento de concretização da dignidade da pessoa humana, enfocando o dever da Administração Pública para a sua efetivação.

\section{$2 \mathrm{O}$ estado liberal e os direitos de liberdade}

A reflexão sobre o dever do Estado na prestação do direito fundamental à saúde implica em voltar o olhar para a história, pois, conforme Ana Paula de Barcellos aponta, sendo um fenômeno humano e histórico, o constitucionalismo contemporâneo não se dissocia da sua própria história (BARCELOS, 2007).

Nessa seara, visualiza-se a evolução do pensamento jurídico a partir 
do período Iluminista, marco do Estado Liberal, que teve como ideia basilar a racionalização do conhecimento, protagonizando relevantes modificações na forma do pensamento. Para alguns historiadores, o período iluminista teve início no século XVII, mas foi no século XVIII que atingiu o ápice, na França, tendo como cenário político o Ancien Regime, caracterizado pela forte oposição ao poder absoluto da nobreza e do clero, que detinham o poder de ditar as leis e regular as relações sociais. Até então, conforme Gustavo Zagrebelski destaca:

[...] el Estado soberano no podía admitir competidores. Si se hubiese permitido una concurrencia, el Estado habría dejado de ser políticamente el 'todo' para pasar a ser simplemente una 'parte' de sistemas políticos más comprensivos, con lo que inevitablemente se habría puesto en cuestión la soberanía y, con ello, la esencia misma de la estatalidad. [...] Frente al Estado soberano no podían existir más que relaciones de sujeción (ZAGREBELSKI, 2007, p. 10).

A filosofia desse movimento defendia a liberdade e a igualdade, fundada no pensamento de que todos nascem livres e assim devem permanecer - buscava-se justificativa para essa assertiva nos direitos naturais da pessoa humana (COSTA, 2013). Os iluministas visavam mudanças na forma de governo, pretendiam acabar com os privilégios de poucos, implantar a livre iniciativa e garantir a igualdade de todos perante a lei, e a defesa da propriedade privada, com pretensão de universalidade. O ideário iluminista, contrapondose ao absolutismo, encontrou respaldo nas aspirações da burguesia e seus interesses capitalistas, e recebeu o apoio do povo que clamava por mudanças sociais e políticas.

O movimento iluminista fez com que o período fosse batizado como o Século das Luzes, encontrando maior força e recepção aos seus princípios na França - palco de problemas econômicos, religiosos, políticos e sociais -, e influenciou a Revolução Francesa, através do ideal do processo revolucionário: Liberdade, Igualdade e Fraternidade (MELLO, 2011).

Conforme Eric J. Hobsbawm consignou sobre a Revolução Francesa, "foi um acontecimento universal e nenhum país estava imune a ela" (HOBSBAWM, 2009, p. 133). Esse evento representou um marco para o Direito cuja expressão máxima é a Declaração Universal dos Direitos do Homem e 
do Cidadão ${ }^{3}$. De acordo com Tercio Sampaio Ferraz Júnior, a neutralização política do judiciário e o lugar privilegiado da lei como fonte de direito, são duas heranças importantes da Revolução ${ }^{4}$. Gustavo Zagrebelski destaca que é nesse momento que vai se delineando o Estado de Direito, de origem liberalburguesa (ZAGREBELSKI, 2007, p. 23), de cunho fortemente individualista e essencialmente formal.

De acordo com Jorge Reis Novais, a característica marcante da feição liberal do Estado de Direito é a separação do Estado em relação à sociedade civil; nessa concepção liberal, o Estado se abstém de interferir nas decisões dos cidadãos, que passam a se desenvolver sem a interferência estatal. $\mathrm{O}$ direito desse período assume, portanto, uma posição jurídica de proteção do indivíduo em face do Estado, delimitando uma esfera de não intervenção do Poder Público, e, por essa razão, os direitos passaram a ser designados direitos de defesa - que impõem ao Estado o dever de abstenção em relação aos indivíduos (NOVAIS (a), 2006, p. 59-72).

Nesse período, o direito à saúde não integrava o rol das prescrições constitucionais, configurando-se como atividade privada. Mas é de se ressaltar que, mesmo nesse período, já era possível identificar, no mundo ocidental, atuações beneficentes na área da saúde, principalmente nas instituições de cunho religioso.

\section{O estado social: gênese dos direitos sociais}

No século XIX, a grande expansão da industrialização e a consequente ocupação urbana revelaram a miséria dos camponeses e as dificuldades dos trabalhadores das cidades submetidos a uma dura realidade. O processo de

\footnotetext{
${ }^{3}$ Cf. Ingo W. Sarlet observa, ainda que haja controvérsia doutrinária a respeito da paternidade dos direitos fundamentais - disputada entre a Declaração de Direitos do povo da Virgínia, de 1776, e a Declaração Francesa, de 1789 - é a primeira que marca a transição dos direitos de liberdade legais ingleses para os direitos fundamentais constitucionais [...] a contribuição francesa, no entanto, foi decisiva para o processo de constitucionalização e reconhecimento de direitos e liberdades fundamentais nas Constituições do século XIX. SARLET. A Eficácia dos Direitos Fundamentais. Porto Alegre: Livraria do Advogado, 2007. p. 51-53.

${ }^{4}$ Cf. observa Ferraz Júnior, a primeira irá provocar uma desvinculação progressiva da teoria jurídica de suas bases políticas, sociais e econômicas, cuja expressão mais conhecida, no século XX, é a Teoria Pura do Direito de Hans Kelsen. A segunda, com a substituição da unidade hierárquica, concretamente simbolizada pelo rex, por uma estrutura complexa de comunicação e controles escondida sob o nome de nação, proporcionará a canalização eficiente de todas as projeções normativas para o endereço político, cuja consequência será o gigantismo do direito estatal. FERRAZ JÚNIOR, Tercio Sampaio. O Legado da Revolução. Disponível em: <http://www.terciosampaioferrazjr. com.br/publicacoes-cientificas/32>. Acesso em: 23 jul. 2015.
} 
industrialização, a exploração dos trabalhadores e a consequente urbanização, resultaram em impactos profundos que se refletiram em problemas sociais e econômicos dos indivíduos. Dessa forma, constatou-se que a liberdade e a igualdade meramente formais, não foram suficientes para o cidadão viver de forma condigna (PIVETTA, 2014, p. 28).

Nesse cenário, surgiu a necessidade de uma proteção aos trabalhadores, incluindo-se a proteção à saúde, bem como a adequação das estruturas de higiene, para o fim de assegurar a continuidade de produção das fábricas e evitar a proliferação de doenças, como observa Mariana Filtchtiner Figueiredo. Assim, o Estado viu-se pressionado para que assumisse a prestação dessas atividades (FIGUEIREDO, 2007, p. 79).

No entanto, conforme Sueli Gandolfi Dallari pontua, verificou-se que a responsabilidade do Estado nas prestações de atendimento à saúde aumentou significativamente no período pós-segunda guerra, quando se impôs a necessidade de reestruturação da infraestrutura sanitária pelos países arrasados em decorrência daquele grave episódio (DALLARI, 2003, p. 34-35).

Em resposta a essa realidade surgiram os movimentos reivindicatórios do século $\mathrm{XX}$, como meio de reação à necessidade de assegurar outros direitos que viessem a contemplar assistência à saúde, à educação e ao trabalho, que culminaram nos direitos sociais. Nesse momento, já não se tratava de impor abstenção do Estado em face dos cidadãos, e, sim, de impor ao Estado os deveres de ações concretas para a proteção dos cidadãos em suas carências, de forma a efetivar a igualdade material (BONAVIDES, 2011, p. 388-399).

Dessa forma, os direitos sociais surgiram na transição entre o Estado Liberal e o Estado Social, em face da necessidade de promoção de bem estar aos cidadãos, e são conquistas dos movimentos sociais ao longo dos séculos, que passaram a ser incorporados, de forma significativa, às Constituições (POTRICH, 2003). Segundo Bobbio, tais direitos nascem "sob a forma de instituição da instrução pública e de medidas a favor do trabalho para os 'pobres válidos que não puderam consegui-lo', fazem a sua primeira aparição no título I da Constituição Francesa de 1791 e são reafirmados solenemente nos artigos 21 e 22 da Declaração dos Direitos de junho de 1793" (BOBBIO, 2004, p. 11)5.

\footnotetext{
${ }^{5}$ A respeito dos direitos sociais, o direito do trabalho se tornou um dos temas do debate acalorado, apesar de estéril, na Assembleia Constituinte francesa de 1848, deixando, todavia, um fraco vestígio no artigo VIII do Preâmbulo. BOBBIO, Norberto. A Era dos Direitos; tradução Carlos Nelson Coutinho; Apres. Celso Lafer. 7. reimpr. Rio de Janeiro: Elsevier, 2004, p. 11. Disponível em: <http://disciplinas.stoa.usp.br/pluginfile.php/297730/ mod_resource/ content/0/norberto-bobbio-a-era-dos-direitos.pdf>. Acesso em: 07 out. 2015.
} 
No entanto, conforme observa Bobbio, ainda que os direitos sociais tenham surgido como um contraponto aos direitos de liberdade:

[...] a mais fundamentada razão da sua aparentemente contradição, mas real complementaridade, com relação aos direitos de liberdade é a que vê nesses direitos uma integração dos direitos de liberdade, no sentido de que eles são a própria condição de seu exercício efetivo. Os direitos de liberdade só podem ser assegurados garantindo-se a cada um o mínimo de bem-estar econômico que permite uma vida digna. Em sua dimensão mais ampla, os direitos sociais entraram na história do constitucionalismo moderno com a Constituição de Weimar (BOBBIO, 2004, p. 11).

De acordo com Jorge Reis Novais, o Estado Liberal já garantia alguns direitos sociais. Para o autor, do ponto de vista jurídico-constitucional, o que distingue os direitos de cunho liberal e social e marca o surgimento os direitos sociais, não é a data de seu nascimento (grifo do autor), mas as diferenças de natureza jurídica que promovem (NOVAIS (c), 2010, p. 21). Observa-se, assim, que "apesar dessa relação extremamente próxima entre política e direitos sociais, permanece inafastável o caráter jurídico de tais direitos" (PIVETTA, 2014, p. 32).

Portanto, os direitos sociais, surgidos como resposta à necessidade de impor ao Estado ações voltadas a promover o bem-estar dos cidadãos, são a pedra de toque para o desenvolvimento das políticas públicas voltadas às necessidades do cidadão. Decorrendo de vários momentos históricos, a sua evolução acentuou-se a partir da Segunda Guerra Mundial, após os horrores vivenciados naquele período, quando se passou a pensar na dignidade da pessoa humana como fundamento dos direitos do homem, princípio incorporado por todos os países que possuem uma Constituição.

\section{A dignidade humana e os direitos fundamentais: pilares do estado democrático de direito}

É importante frisar que, na medida em que se afirmam direitos fundamentais, concebidos historicamente como produto da alteração das condições sociais, surge num Estado democrático de Direito a necessidade de 
se proporcionar a sua efetivação, como forma de concretização da dignidade humana. De acordo com as reflexões de Jorge Reis Novais:

[...] é porque se reconhece a todas as pessoas igual dignidade, e, porque, no relacionamento com os poderes públicos, a pessoa humana é elevada à condição de fim último justificador da própria existência do Estado, que as Constituições consagram um elenco de direitos fundamentais destinados a assegurar juridicamente a autonomia, a liberdade e uma vida condigna a todos os cidadãos (NOVAIS (b), 2015, p. 69).

Conforme o autor observa, "é através do reconhecimento da sua dignidade que a pessoa se alça à qualidade de sujeito jurídico". Nessa perspectiva, a dignidade humana, mais do que um direito, ou mais do que uma garantia jurídica, é considerada como um "verdadeiro direito originário a ter direitos" (Cf. ENDERS, 2009, p. 74, apud NOVAIS (b), 2015, p. 70).

Com base nesses pensamentos, firma-se o entendimento de que o Estado não dispõe dos direitos fundamentais, mas antes, cabe-lhe respeitar, garantir, proteger e promover o desenvolvimento como forma de concretizar a ideia de República fundamentada na dignidade da pessoa humana (NOVAIS (b), 2015, p. 70).

Alinhado a essas ideias, Jorge Reis Novais menciona o pensamento de Dürig ${ }^{6}$, ao destacar que a dignidade da pessoa humana é a base em que assenta a República, representa o princípio fundamental na ordem dos valores que orienta o relacionamento jurídico entre Estado e indivíduo; portanto, "influi na conformação jurídica da natureza e do alcance dos direitos fundamentais" (Cf. DÜRIG, apud NOVAIS (b), 2015, p. 72).

Nesse contexto, a dignidade da pessoa humana é o "fundamento da consagração constitucional dos direitos fundamentais destinados a assegurar a autonomia, a liberdade e uma vida condigna a todos os cidadãos (incluindo-se potencialmente nesse elenco os direitos de liberdade, de igualdade, de participação política e os direitos sociais)". Portanto, se o Estado reivindica para si a qualificação de Estado de Direito, todo o poder público fica vinculado juridicamente, e obrigado a respeitar e a observar os direitos fundamentais (NOVAIS (b), 2015, p. 73).

A dignidade da pessoa humana representa, portanto, a gênese do

${ }^{6}$ Cf. DÜRIG, Der Grundrechtssatz Von der Menschenwürde, cit. p. 118, p. 123 e ss. Apud. NOVAIS, A dignidade da pessoa Humana. Dignidade e Direitos fundamentais. Coimbra: Almedina, 2015. p. 72. 
sistema dos direitos fundamentais, e, "reciprocamente, cabe aos direitos fundamentais concretizar, desenvolver e garantir a vinculação do Estado e dos poderes públicos ao comando constitucional" (NOVAIS (b), 2015, p. 75). Sob essa perspectiva é que se identifica a responsabilidade do Estado para o bem estar do cidadão, como forma de promover os direitos fundamentais.

Nesse sentido convergem os ensinamentos de J. J. Gomes Canotilho, ao expressar: "[...] como são um elemento constitutivo do Estado de Direito, os direitos fundamentais são um elemento básico para a realização do princípio democrático [...] coenvolve a abertura do processo político no sentido da criação de direitos sociais, econômicos e culturais, constitutivos de uma democracia econômica, social e cultural" (CANOTILHO, 2003, p. 290).

Nessa linha de pensamento, Paulo Ricardo Schier destaca que "[...] é a partir dos direitos fundamentais (pois são os direitos vinculados à proteção do homem) que se deve compreender uma Constituição [...] justificam a criação e desenvolvimento de mecanismos de legitimação, limitação, controle e racionalização do poder" (SCHIER, 2011, p. 04).

Conforme o pensamento de Gustavo Binenbojm, as premissas dos direitos fundamentais e democracia "representam duas das maiores conquistas da moralidade política em todos os tempos", e toda a discussão sobre o que é, para que serve e qual a origem da autoridade (grifos do autor) do Estado e do direito, direcionam-se para as relações entre a teoria dos direitos fundamentais e a teoria democrática (BINENBOJM, 2008, p. 45). E sendo o princípio da dignidade humana o norteador da Constituição de 1988, não resta dúvida de que promove a aproximação da moral e do direito, que passa a refletir no Direito Administrativo.

Dessa forma, de acordo com o autor, ainda que existam diferentes fundamentações teóricas, há, na atualidade, certo consenso de que os direitos fundamentais e democracia são elementos constitutivos do Estado Democrático de Direito, e a Constituição é o instrumento pelo qual esses direitos se institucionalizam no âmbito do Estado (BINENBOJM, 2008, p. 45).

\section{A Constituição Federal de 1988 e o papel da administração pública na realização dos direitos fundamentais - o direito prestacional à saúde}

No Brasil, o marco histórico da mudança de paradigma na conduta do Poder Público em relação ao cidadão é a Constituição Federal de 1988, 
que inovou ao contemplar a dignidade da pessoa humana como princípio fundamental estruturante da Carta Magna, irradiando seus efeitos para todo o ordenamento jurídico.

A partir dessa concepção, o ser humano passa a ser o centro do interesse do Estado, e, de acordo com Paulo Ricardo Schier, "desenvolveu-se a ideia de filtragem constitucional [...] que permite pensar o Direito Constitucional em sua perspectiva jurídico-normativa em diálogo com as realidades social, política e econômica" (SCHIER, 2005, p. 02).

Nesse sentido, Gustavo Binenbojm destaca que "a passagem da Constituição para o centro do ordenamento jurídico representa a grande força motriz da mudança de paradigmas do direito administrativo na atualidade", sendo importante ressaltar os dispositivos constitucionais que conferem ao Estado o dever de proteção e de promoção do ser humano (BINENBOJM, 2008, p. 25). Considerando que os direitos fundamentais e o princípio democrático são os pilares constitutivos e legitimadores da ordem constitucional, representam as diretrizes que orientam e submetem as atividades e atos da Administração Pública.

Como referencial histórico, a inserção dos mandamentos constitucionais na seara da Administração Pública tem início a partir das Constituições italiana e alemã, e foi consideravelmente ampliado nas Constituições espanhola e portuguesa. No caso brasileiro, a Constituição de 1988 disciplinou de forma minuciosa as atribuições da Administração Pública, e, conforme Gustavo Binenbojm ressalta, "exibe uma feição corporativa muito mais nítida que qualquer preocupação garantística" (grifos do autor) (BINENBOJM, 2008, p. 25). No entanto, pondera o autor, a Constituição acrescentou aos princípios setoriais do direito administrativo, antes legalidade, impessoalidade, moralidade e publicidade, com a Emenda Constitucional $n^{\circ} 19 / 98$, o princípio da eficiência. Assim, na perspectiva constitucional, o agir administrativo encontra os limites diretamente em regras ou princípios constitucionais, prescindindo da mediação do legislador as ações ou omissões da Administração Pública (BINENBOJM, 2008, p. 48-49).

Conforme Clèmerson Merlin Clève expressa, "sob a égide da Constituição Federal de 1988, o Estado, espaço político por excelência, haverá de ser compreendido como uma espécie de ossatura institucional desenhada pelo Constituinte para satisfazer os princípios, objetivos e direitos fundamentais através da atuação do Legislativo". E nessa perspectiva, incumbe ao Executivo 
desenvolver políticas públicas voltadas para a concretização dos dispositivos constitucionais, onde se incluem os direitos prestacionais de saúde e educação, entre outros (CLÈVE, 2011, p. 99).

Nesse sentido, a moderna dogmática dos direitos fundamentais sociais, cuida da obrigação do Estado "para a criação dos pressupostos fáticos necessários ao exercício efetivo dos direitos constitucionalmente assegurados, e a possibilidade do titular do direito impor sua pretensão a prestações em face do Estado" (RAMOS, 2010, p. 57).

Sob esse prisma, os direitos fundamentais sociais positivos têm a função de assegurar, mediante prestações materiais, "a compensação das desigualdades sociais, proporcionando o exercício de liberdade e igualdade reais e efetivas, o que pressupõe um comportamento ativo do Estado, já que a igualdade material não se oferece simplesmente por si mesma, devendo ser devidamente implementada" (SARLET, 2007 (a), p. 202 e ss).

Nessa perspectiva, Alexandre Santos Aragão destaca que, "de acordo com a exposição descritiva dos dispositivos constitucionais da Constituição Federal de 1988 relacionados com a temática dos serviços públicos, podemos concluir que a República Federativa do Brasil é, por excelência, um Estado prestacional, com uma série de obrigações com a sua população" (ARAGÃO, 2009, p. 19).

No que tange à saúde, observa Saulo Lindorfer Pivetta, o direito a prestações determina que o Poder Público adote condutas positivas de natureza fática e normativa. Em sentido amplo, impõe que sejam tomadas medidas de proteção, instituindo procedimentos de estrutura e organização, de modo a viabilizar a proteção e promoção da saúde, para suprir as demandas da população nessa seara (PIVETTA, 2014, p. 44).

Na esfera de prestação do direito à saúde pelo Poder Público, em sentido estrito, compreende as mais diversas atuações positivas de natureza fática, de modo a garantir ao cidadão o efetivo acesso a bens e serviços de saúde, tais como o dever de construção de hospitais públicos, manutenção de atendimento adequado nos postos de saúde, fornecimento de medicamentos aos que não têm meios próprios para obtê-los, dentre outras atividades pertinentes à saúde (PIVETTA, 2014, p. 45).

Conforme o autor, a norma constitucional garantidora de direito social, de natureza positiva - que impõe condutas prestacionais - ainda que não defina detalhadamente o conteúdo prestacional do direito, "impõe aos demais 
órgãos do Estado e ao legislador infraconstitucional o dever de conformá-lo, como decorrência da própria dimensão objetiva dos direitos fundamentais" (PIVETTA, 2014, p. 61).

Entretanto, Clèmerson Merlin Clève observa que esses direitos são dependentes de uma manifestação legislativa e material do Estado, e insuscetíveis de realização integral. Conforme o autor expressa, "o horizonte é sempre infinito" (grifo nosso), pois para o seu cumprimento implica no grau de riqueza da sociedade, e da alocação de recursos públicos, e da previsão das receitas (CLÈVE, 2011, p. 99).

A esse respeito, Jorge Reis Novais destaca que a efetivação das prestações demandam recursos financeiros, e se encontram sujeitas à incidência da reserva do financeiramente possível (NOVAIS, 2010 (c), p. 147), o que representa limitação ou restrição à efetivação dos direitos fundamentais sociais. Tal fato é motivo de fortes discussões doutrinárias, por colocar em confronto o direito social prestacional do cidadão em face das possibilidades financeiras do Poder Público.

Nesse sentido, Ana Paula de Barcellos observa que a definição dos gastos públicos "é um momento típico da deliberação político-majoritária, salvo que essa deliberação não estará livre de alguns condicionantes jurídicoconstitucionais" (BARCELLOS, 2007, p. 14).

Para a autora, não é possível afirmar que todas as prestações existentes são viáveis, considerando que poderia "esvaziar o espaço de escolha política na matéria e conduzir os recursos públicos a uma possível exaustão, tendo em conta a progressiva sofisticação e o incremento de custos dos serviços de saúde". Por outro lado, pondera, essa realidade "não significa que não haja um conjunto de prestações mínimas que deva ser ofertado pelo Estado" (BARCELLOS, 2007, p. 21-22).

Nessa questão, é relevante o posicionamento de Ana Lucia Pretto Pereira ao consignar que "a diferença crucial e determinante ao acolhimento ou não do argumento da reserva do possível, é identificar se os satisfatores - bens econômicos - demandados atendem às necessidades humanas ou às necessidades humanas fundamentais" (grifos da autora). Para a autora, o argumento da escassez de recursos pode restringir a satisfação de preferências, apenas; por outro lado, ressalta: "tratando-se do atendimento de necessidades humanas fundamentais, em sentido estrito, sai-se do campo da preferência e entra-se no campo da exigência" (grifos da autora). São direitos básicos que dizem respeito 
à vida e à integridade e não podem ficar dependentes da previsão orçamentária (PEREIRA, 2009, p. 28-29).

Nesse sentido, importa observar que os direitos sociais (negativos e positivos) encontram-se sujeitos à lógica do artigo $5 .^{\circ}$, parágrafo $1 .^{\circ}$ da Constituição Federal $^{7}$, no sentido de que a todas as normas de direitos fundamentais (inclusive de cunho prestacional) se devem outorgar a máxima eficácia e efetividade possível, no âmbito de um processo de otimização, pautado pelo conjunto de princípios fundamentais (SARLET (a), 2007, p. 562-63 e 282 e ss.).

Conforme Clèmerson Merlin Clève defende, "os direitos entendidos como prestacionais são direitos de eficácia progressiva e não são, pois, meras normas de eficácia diferida, programática, limitada"; assim, decorrentes do reconhecimento dos direitos fundamentais, as prestações do poder público poderão ser progressivamente incrementadas (CLÉVE, 2011, p. 106).

\section{A Constituição brasileira e o direito fundamental à saúde}

A Constituição de 1988, que proclama como princípio fundamental e estruturante do Estado Democrático de Direito e da ordem jurídica, inserida no art. $1 .^{\circ}$, inciso III, a dignidade da pessoa humana, foi pioneira ao determinar saúde como direito fundamental ao garantir em seu artigo $5^{\circ}$, caput, a inviolabilidade do direito à vida. De acordo com Alexandre de Moraes, "o direito à saúde é indissociável ao direito à vida, o mais fundamental de todos os direitos, e pré-requisito à existência e exercício de todos os demais direitos" (MORAES, 2012, p. 34).

Segundo José Afonso da Silva, "no qualificativo fundamentais (grifo do autor) acha-se a indicação de que se trata de situações jurídicas sem as quais a pessoa humana não se realiza, não convive e, às vezes, nem sempre sobrevive; fundamentais do homem no sentido de que a todos, por igual, devem ser, não apenas formalmente reconhecidos, mas concreta e materialmente efetivados" (SILVA, 2000, p. 182). De acordo com o constitucionalista, "[...] os direitos sociais (grifo do autor), são a dimensão dos direitos fundamentais do homem” (SILVA, 2000, p. 289). Nesse sentido, "verifica-se, em primeiro lugar, que o princípio da dignidade da pessoa humana e o próprio direito à vida se encontram [...] na base de todos os direitos sociais em exame" (SARLET, 2007 (a), p. 342).

${ }^{7}$ Art. $5 .^{\circ}$, p. $1^{\circ}$ da CF/1988: "as normas definidoras dos direitos e garantias fundamentais têm aplicação imediata". 
O direto à saúde, disciplinado em vários artigos da Carta Constitucional e inserido no rol dos direitos sociais, é um direito fundamental, previsto na redação do artigo $6 .^{\circ}$, da Constituição Federal de 1988: "são direitos sociais a educação, a saúde, o trabalho, a moradia, o lazer, a segurança, a previdência social, a proteção à maternidade e à infância, a assistência aos desamparados, na forma dessa Constituição". Tal direito foi consagrado, ainda, em diversos dispositivos constitucionais, que norteiam a ordem jurídica no país, consagrando o direito à saúde como um direito fundamental do homem, direito social e dever do Estado, conforme se verifica:

Art. 196. A saúde é direito de todos e dever do Estado, garantido mediante políticas sociais e econômicas que visem à redução do risco de doença e de outros agravos e ao acesso universal e igualitário às ações e serviços para sua promoção, proteção e recuperação.

Art. 197. São de relevância pública as ações e serviços de saúde, cabendo ao Poder Público dispor, nos termos da lei, sobre sua regulamentação, fiscalização e controle, devendo sua execução ser feita diretamente ou através de terceiros e, também, por pessoa física ou jurídica de direito privado.

A esse respeito, observa-se que o texto constitucional não apenas define expressamente a saúde como direito de todos, mas também especifica que é o Estado o principal titular do dever. Daí porque a conclusão de que, no ambiente do Estado Democrático e Social de Direito, cabe à Administração Pública o principal dever de sua concretização, mediante a prestação de serviços públicos (PIVETTA, 2011, p. 428).

\section{A administração pública e a efetivação do direito fundamental à saúde}

A Constituição de 1988 promoveu profunda alteração na seara administrativa pátria, pois identifica-se um "regime jurídico constitucionaladministrativo, fundado em princípios constitucionais expressos: legalidade, impessoalidade, moralidade, publicidade e eficiência (art. 37, caput)" (BACELLAR FILHO, 2012, p. 27).

É importante ressaltar que a referência a esse momento constitucional 
da Administração Pública é a constitucionalização do Direito, fenômeno que impõe a irradiação das normas constitucionais para todo o ordenamento jurídico, e que vincula o agir dos Poderes Públicos, de todas as esferas, às regras e princípios conforme determina a Constituição.

Em relação às atividades da Administração Pública, a constitucionalização do Direito promove: "a limitação da discricionariedade administrativa; a imposição de deveres positivos de conduta; a outorga de fundamento normativo para a realização de atos vinculados diretamente à Constituição, e independentemente do legislador infraconstitucional" (CLÈVE, 2012, p. 158). Desse modo, a constitucionalização do Direito, no que tange à Administração Pública, estabelece não apenas um regime jurídico constitucionaladministrativo' que disciplina o seu agir, mas, também, impõe que se realizem objetivos, como os direitos sociais (PIVETTA, 2014, p. 93).

No que diz respeito à saúde, conforme Ingo Wolfgang Sarlet ressalta, "é dever do Estado a proteção ativa da vida humana, já que essa constitui a própria razão de ser do Estado, além de pressuposto para o exercício de qualquer direito". Para o autor, a dignidade humana impõe a prestação de padrões mínimos de prestação, e que "não poderá se reduzir apenas a um mínimo vital"8 (SARLET (a), 2007, p. 375 e ss.).

Portanto, considerando o vínculo que a Constituição impõe ao Poder Público na prestação de direitos sociais, é dever da Administração Pública as políticas de estruturação de procedimentos e instituições que viabilizem a proteção de acesso aos bens protegidos constitucionalmente (PIVETTA, 2014, p. 99), conforme se verifica em vários dispositivos da Constituição ${ }^{9}$, e pode-se entender por planejamentos de programas e ações estratégicas para a promoção do atendimento ao cidadão.

No que diz respeito ao objeto desse estudo, as políticas públicas de saúde são os mecanismos de estruturação, planejamento e diretrizes das ações da Administração Pública, para definir as prioridades do cidadão a serem prestadas pelo poder público, no intuito de concretizar da melhor forma os

\footnotetext{
${ }^{8} \mathrm{O}$ tema do mínimo existencial, ainda que de grande relevância para o tema central, não será abordado neste estudo.

${ }^{9}$ A título de exemplificação, na Constituição de 1988 verifica-se o termo políticas públicas no art. 22, IX "a política nacional de transportes"; no art. 204, II "a exigência de participação popular na formulação de políticas de assistência social"; no art. 227, parágrafo $1 .^{\circ}$, "no dever do Estado de promover políticas específicas para a promoção da assistência integral à saúde da criança" [...], entre outros dispositivos constitucionais.
} 
direitos fundamentais sociais, de acordo com os objetivos constitucionais. Dentre os instrumentos de políticas públicas do Estado, na área da saúde, destaca-se o serviço público, que será objeto do próximo item.

\section{Serviços públicos: instrumento de concretização do direito fundamental à saúde}

O serviço público, nascido no bojo do Estado Social, é a atividade prestacional titularizada pelo Estado, prestada por ele ou por quem lhe faça as vezes, regida por um regime jurídico especial de prerrogativas e sujeições, voltada à realização dos direitos fundamentais, notadamente, à dignidade da pessoa humana (JUSTEN FILHO, 2005, p. 480). A definição de uma dada atividade como serviço público, de matriz constitucional, remete ao plano das opções políticas do Estado (MEDAUAR, 2011, p. 335) e, por isso, "o serviço público é a tradução jurídica do compromisso político da intervenção estatal para satisfazer as necessidades coletivas" (JUSTEN FILHO, 2003, p. 23).

Nesse sentido, ao definir o serviço público numa perspectiva material, Juarez Freitas entende que "serviço público é todo aquele essencial para a realização dos objetivos fundamentais do Estado Democrático, devendo, por isso mesmo, ser prestado sob o regime peculiar juspublicista" (FREITAS (a), 1995, p. 31). Referindo-se às funções essenciais a serem prestadas pela Administração Pública no Estado Democrático, o autor ressalta que "o Estado só se legitima como defensor máximo dos Direitos, fora do qual seria uma simples e tentacular máquina de repressão" (FREITAS (b), 1999, p. 55-56).

A partir dessas aproximações, identifica-se o serviço público como o instrumento, por excelência, de realização de direitos fundamentais. Não por outro motivo, é o catálogo de tais direitos em cada modelo de Estado que identifica o rol dos serviços públicos prestados. Por isso, no Estado Liberal os serviços públicos voltavam-se basicamente para implantação de infraestruturas - vinculando-se ao interesse privado no desenvolvimento econômico.

Já no Estado Social, as prestações estarão vinculadas, também, à realização dos direitos sociais. Conforme Adriana da Costa RicardoSchier observa, "essa alteração da função do instituto do serviço público reflete na noção de desenvolvimento, que traduz a busca por uma noção que seja satisfatória à maioria dos cidadãos e que abarque fins sociais", e dessa forma, "o desenvolvimento passa a ser qualificado pelo adjetivo humano" (A. SCHIER, 2011, p. 289). 
$\mathrm{Na}$ perspectiva do desenvolvimento, no que diz respeito à implementação dos serviços públicos na redemocratização do Estado brasileiro, passou-se a perceber os serviços públicos como o conjunto de ofertas positivas básicas e indispensáveis à sociedade para uma vida digna, assumidas pelo Poder Público, vinculados à efetivação dos direitos fundamentais sociais, consagrados pela Constituição (A. SCHIER, 2011, p. 289).

Portanto, à luz da Carta Magna, a constitucionalização dos direitos sociais envolve "o instituto do serviço público como o objeto de intervenção estatal pelo qual será assegurada a efetividade desses direitos, diretamente ligados à concretização da dignidade de todas as pessoas" (A. SCHIER, 2011, p. 290).

Partindo-se desses pressupostos, o direito à saúde, consagrado como direito fundamental na Carta, impõe ao poder público o dever de sua realização, mediante a prestação de serviços públicos universais e contínuos, que possam assegurar aos cidadãos o direito a uma vida boa, digna. Entretanto, diante da realidade cotidiana, que indica patamares ínfimos na realização plena desse direito, será possível afirmar, de fato, a universalidade e a efetividade de tal direito no cenário nacional?

\section{$9 \mathrm{O}$ direito à saúde: realidade ou garantia simbólica?}

As políticas públicas de saúde no Brasil têm como marco histórico a Constituição de 1988, com a criação do Sistema Único de Saúde - SUS. De acordo com dados oficiais, antes de 1998, 30 milhões de pessoas tinham efetivo acesso a serviços de saúde pública, e com a implantação do SUS, estima-se que 190 milhões de brasileiros foram atendidos por esse sistema de saúde (Cf. MINISTÉRIO DA SAÚDE, 2009) ${ }^{10}$. Conforme definição do Ministério da Saúde:

[...] o SUS é uma conquista da sociedade brasileira e foi criado com o firme propósito de promover a justiça social e superar as desigualdades na assistência à saúde da população, tornando obrigatório e gratuito o atendimento a todos os indivíduos. Abrange do simples atendimento ambulatorial aos transplantes de órgãos e é o único a garantir acesso integral, universal e igualitário (MINISTÉRIO DA SAÚDE, 2009).

\footnotetext{
10 Observa-se que esses dados são de 2009, portanto, para o presente estudo serve tão somente como parâmetro para compreender a abrangência da prestação dos serviços de saúde pública antes e depois da Constituição de 1988, com a implantação do SUS.
} 
Constata-se, assim, o esforço do Poder Público no cumprimento desse dever constitucional na seara da saúde mediante o Sistema Único de Saúde, presente em todos os Estados e na grande maioria das cidades do País, uma vez que admitir a previdência como direito fundamental é uma necessidade (IBRAHIM, 2010, p. 1059-60).

No entanto, a realidade demonstra que o sistema não é suficiente para o atendimento da forma idealizada na Carta Magna. Deficiências de atendimento ocorrem a todo instante e constata-se que o cidadão, ao recorrer ao sistema de saúde pública, seja nos ambulatórios ou hospitais públicos, muitas vezes deixa de ser atendido, ou ainda, devido ao tempo de espera a medida passa a ser ineficaz.

Voltando o olhar para o passado, não há dúvida de que houve avanços significativos, no entanto, a realidade vem demonstrando que o atendimento às necessidades de saúde não acompanha a demanda, e esse descompasso evidencia que os objetivos constitucionais de uma sociedade justa e equilibrada ainda estão longe de acontecer.

Conforme Norberto Bobbio consignou "[...] o mais forte argumento adotado pelos reacionários de todos os países contra os direitos do homem, particularmente contra os direitos sociais, não é a sua falta de fundamento, mas a sua inexequibilidade". Assim, observa o autor, "[...] quando se trata de enunciá-los, o acordo é obtido com relativa facilidade, independentemente do maior ou menor poder de convicção de seu fundamento absoluto; quando se trata de passar à ação, ainda que o fundamento seja inquestionável, começam as reservas e as oposições" (BOBBIO, 2004, p. 15-16).

Nesse sentido, ainda que a Constituição determine amplamente a prestação da assistência à saúde, conforme observa Sueli Gandolfi Dallari, "não basta apenas declarar que todos têm direito à saúde"; é indispensável que a Administração Pública assuma o papel de encontrar as saídas para resolver essa questão (DALLARI, 1988, p. 60). Dessa forma, considerando a realidade da prestação da saúde no Brasil em face da previsão constitucional, surge o questionamento: a prestação da saúde no Brasil é uma realidade ou ainda é uma garantia simbólica?

Nas palavras de Sueli Gandolfi Dallari, "fica evidente a dificuldade que existe para a garantia do direito, quando se considera a amplitude da significação do termo saúde e a complexidade do direito à saúde, que depende daquele frágil equilíbrio entre a liberdade e a igualdade, quando há necessidade 
de reconhecimento do direito do Estado ao desenvolvimento do cidadão" (DALLARI, 1988, p. 57-63).

Portanto, repensar o direito social à saúde como garantia efetiva ao cidadão, e a obrigatoriedade da prestação de serviços públicos nessa área, é uma necessidade, pois somente no momento em que se atinja um nível de atendimento que assegure prestações de forma a garantir uma vida com qualidade para todos, é que estará garantida a dignidade de todos os cidadãos, como preconiza a Carta Magna, deixando de ser visto o direito à saúde como uma garantia simbólica.

\section{Conclusão}

Neste estudo, procurou-se abordar o direito fundamental social à saúde a partir da sua origem, para melhor compreender o dever do Estado na sua prestação, como resultado de lutas históricas. Centrou-se na Constituição de 1988, que tem como fundamento maior o princípio da dignidade humana, marco da inserção e consagração dos direitos fundamentais sociais, identificando-se, a partir daí, o dever imposto ao Poder Público de assegurar o bem estar aos cidadãos, mediante a prestação de assistência às suas necessidades básicas.

Nessa medida, cabe à Administração Pública o papel de efetivação do direito fundamental social à saúde, por meio da prestação de serviço público, como mecanismo de concretização dos direitos fundamentais, contemplando a dignidade da pessoa humana num ambiente de democracia.

Entretanto, não obstante as relevantes iniciativas e ações do Poder Público na promoção de serviços de saúde, constata-se que a prestação nesta área ainda é deficitária e não acompanha a demanda. Nesse sentido, considerando que a realização dos direitos sociais implica em custos, e, na medida em que a arrecadação dos cofres públicos não é suficiente para contemplar a todas as necessidades, aponta-se como um dos fatores dessa deficiência a escassez de recursos.

De qualquer modo, diante dos números apresentados pelo orçamento público, é possível argumentar que o déficit da prestação da saúde pública não pode ser atribuído tão somente à escassez de recursos, mas, em grande parte, tratase de um grave problema de gestão pública dos recursos financeiros. E, nessa seara, pode-se concluir que a má gestão financeira deve ser encarada como um grave desvio das finalidades da Administração Pública e dos objetivos constitucionais, e um dos maiores entraves para a prestação eficiente da saúde pública. 


\section{Referências}

ARAGÃO, Alexandre dos Santos. O Conceito de Serviço Público no Direito Constitucional Brasileiro. Revista Eletrônica de Direito Administrativo Econômico (REDAE), Salvador, Instituto Brasileiro de Direito Público, n. ${ }^{\circ}$ 17, fevereiro/março/ abril, 2009. Disponível em: http://www.direitodoestado.com/ revista/redae-17fevereiro-2009-alexandre\%20aragao.pdf. Acesso em: 24 maio 2016.

ASCENÇÃO, José de Oliveira. O Direito Introdução e Teoria Geral. Uma perspectiva luso-brasileira. 2. ed. revisada e ampliada. Rio de Janeiro: Renovar, 2001.

BACELLAR FILHO, Romeu Felipe. Processo Administrativo Disciplinar. 3. ed. São Paulo: Saraiva, 2012.

BARCELLOS, Ana Paula de. Neoconstitucionalismo, Direitos Fundamentais e Controle das Políticas Públicas. Salvador: Revista Diálogo Jurídico, n.15, jan/2007. Disponível em: <http:/ / www.direitopublico.com.br>. Acesso em: 22 jul. 2015.

BINENBOJM, Gustavo. Temas de Direito Administrativo e Constitucional: artigos e pareceres. Rio de Janeiro, São Paulo, Recife: Renovar, 2008.

BOBBIO, Norberto. A Era dos Direitos. Tradução Carlos Nelson Coutinho. Apres. Celso Lafer. 7. reimpr. Rio de Janeiro: Elsevier, 2004. p. 11. Disponível em: http:// disciplinas.stoa.usp.br/ pluginfile.php/297730/mod_ resource/content/0/ norberto-bobbio-a-era-dos-direitos.pdf. Acesso em: 07 out. 2015.

BONAVIDES, Paulo. Curso de Direito Constitucional. 27. ed. São Paulo: Malheiros, 2011.

BRASIL. Constituição da República Federativa do Brasil. 1988. Disponível em: http://www.planalto.gov.br/ccivil_03/constituicao/constituicaocompilado.htm.

CLÈVE, Clèmerson Merlin. A Eficácia dos Direitos Fundamentais Sociais. In: BACELLAR FILHO, Romeu Felipe; GABARDO, Emerson; HACHEM, Daniel Wunder (Coords.). Globalização, Direitos Fundamentais e Direito Administrativo: Novas Perspectivas para o Desenvolvimento Econômico e Socioambiental. Belo Horizonte: Fórum, 2011. 
Fórum, 2012.

Para Uma Dogmática Constitucional Emancipatória. Belo Horizonte:

CANOTILHO, J. J. Gomes. Direito Constitucional e Teoria da Constituição. 7. ed. Coimbra: Almedina, 2003.

COSTA, Carlos Eduardo de Carvalho. Direito Natural e Iluminismo: influência na formação do raciocínio jurídico moderno. Conteúdo Jurídico, BrasíliaDF: 30 jul.de 2013. Disponível em: http:// www.conteudojuridico.com. br/?colunas\&colunista=46343_Carlos_Costa\&ver=1607. Acesso em: 21 jul. 2015.

DALLARI, Sueli Gandolfi. O direito à saúde. Rev. Saúde pública. S. Paulo, 22:57-63, 1988. Disponível em: <http://www.scielo.br/pdf/rsp/v22n1/08.pdf>. Acesso em: 11 jun. 2016.

FERRAZ JÚNIOR, Tercio Sampaio. O Legado da Revolução. Disponível em: <http://www.tercio sampaioferrazjr.com.br/publicacoes-cientificas/32>. Acesso em: 23 jul. 2015.

FIGUEIREDO, Mariana Filchtiner. Direito Fundamental à Saúde: parâmetros para sua eficácia e efetividade. Porto Alegre: Livraria do advogado, 2007.

FREITAS, Juarez (a). Estudos de Direito Administrativo. São Paulo: Malheiros, 1995.

(b) O Controle dos Atos Administrativos. 2. ed. atualizada e ampliada. São Paulo: Malheiros, 1999.

HOBSBAWM, Eric J. A Era das Revoluções. 24. ed. São Paulo: Paz e Terra, 2009.

IBRAHIM, Fábio Zambitte. A previdência Social Como Direito Fundamental. In: SOUZA NETO, Cláudio Pereira; SARMENTO, Daniel. (Coords.) Direitos Sociais, Fundamnetos, Judicialização e Direitos Sociais em Espécie. 2. ed. Rio de Janeiro: Lumen Iuris, 2010. p. 1053-1082.

JUSTEN FILHO, Marçal. Teoria geral das concessões de serviço público. São Paulo: Dialética, 2003.

Curso de Direito Administrativo. São Paulo: Saraiva, 2005. 
MELLO, Vico Denis S.; Donato, M. R. O Pensamento Iluminista e o Desencantamento do Mundo. Revista Crítica Histórica. Ano II, no 4, Dezembro / 2011 ISSN 21779961. Disponível em <http://www.revista.ufal.br/criticahistorica/attachments/ article/18/>. Acesso em: 22 jul. 2015.

MINISTÉRIO DA SAÚDE. Biblioteca Virtual em Saúde. Sus: A Saúde do Brasil. Coleção Institucional. Biblioteca Virtual em Saúde. Disponível em: http://bvsms. saude.gov.br/bvs/publicacoes/sus_saude_brasil_3ed.pdf. Acesso em: 19jun. 2016. NOVAIS, Jorge Reis (a). Contributo para uma teoria do Estado de Direito. Coimbra: Almedina, 2006. p. 59-72.

(b) A Dignidade da pessoa Humana. Dignidade e Direitos Fundamentais. vol. 1. Coimbra: Almedina. 2015.

(c) Direitos Sociais. Teoria Jurídica dos Direitos Sociais Enquanto Direitos Fundamentais. Coimbra: Coimbra, 2010.

PEREIRA, Ana Lucia Pretto. A Reserva do Possível na Jurisdição Constitucional Brasileira: entre constitucionalismo e democracia. Dissertação (mestrado) - Universidade Federal do Paraná, Setor de Ciências Jurídicas, Programa de Pós-Graduação em Direito. Defesa. Curitiba, 2009, p. 28-29. Disponível em: <http:/ /200.17.203.155/index.php?codigo_sophia=257478>. Acesso em: 06 set. 2015.

PIVETTA, Lindorfer Saulo. Direito fundamental à Saúde. Regime jurídico, políticas públicas e controle judicial. São Paulo: Revista dos Tribunais. 2014.

POTRICH, Felipe Bittencourt. Efetividade dos Direitos Sociais, Reserva do Possível e seus Limites. Disponível em: <www.agu.gov.br/page/download/ index/id/>. Acesso em: 06 set. 2015.

RAMOS, Marcelene Carvalho da Silva. Revista Jurídica da Procuradoria Geral do Estado do Paraná, Curitiba, n. 1, p. 53-92, 2010, p. 57. Disponível em: <http:/ /www. pge.pr.gov.br/ arquivos/File/Revista_PGE_2010/04_O_direito_fundamental. pdf>. Acesso em: 11 Abr. 2016.

SARLET, Ingo W. (a) A Eficácia dos Direitos Fundamentais. 7. ed. revista, atualizada e ampliada. Porto Alegre: Livraria do Advogado, 2007.

(b) Algumas Considerações em torno do Conteúdo, Eficácia e Efetividade do direito à saúde na Constituição de 1988. Salvador: Bahia. Instituto Brasileiro de 
direito Público IBDP. Revista Eletrônica Sobre a Reforma do Estado, n. 11, set/ out/nov/ 2007. Disponível em: <http://www.direitopublico.com.br>. Acesso em: 18 jun. 2016.

(c) Direitos Fundamentais Sociais. "Mínimo Existencial" e Direito Privado: breves notas sobre alguns aspectos da possível eficácia dos direitos sociais nas relações entre particulares. In: SARMENTO, Daniel; GALDINO Flávio. Direitos Fundamentais: estudos em homenagem ao professor Ricardo Lobo Torres. Rio de janeiro, São Paulo, Recife: Renovar, 2006.

SCHIER, Paulo Ricardo. Ensaio sobre a supremacia do interesse público sobre o privado e o regime jurídico dos direitos fundamentais. Revista Eletrônica de Direito Administrativo Econômico (REDAE). Salvador. Instituto Brasileiro de Direito Público da Bahia, $\mathrm{n}^{\circ}$. 26, maio/junho/julho, 2011. Disponível em: <http:/ / www.direitodoestado.com/revista/redae-26-maio-2011-paulo-schier.pdf $>$. Acesso em: 15 abr. 2016.

Novos Desafios da Filtragem Constitucional no Momento do Neoconstitucionalismo. Revista Eletrônica de Direito do Estado (REDAE). Salvador. Instituto de Direito Público da Bahia, n. 04, outubro/novembro/dezembro, 2005. Disponível em: <http:/ / www.direitodoestado.com.br>. Acesso em: 14 jun. 2016.

SCHIER, Adriana da Costa Ricardo. Serviço Público Como Direito Fundamental: Mecanismo de Desenvolvimento Social. In: BACELLAR FILHO, Romeu Felipe; HACHEN, Daniel Wunder (orgs). Globalização, Direitos Fundamentais e Direito Administrativo. Novas Perspectivas Para O Desenvolvimento Econômico e Socioambiental. Belo Horizonte: Fórum, 2011. p. 285-296.

SILVA, José Afonso da. Curso de Direito Constitucional Positivo. Teoria dos Direitos Fundamentais do Homem. 17. ed. São Paulo: Malheiros, 2000.

ZAGREBELSKI, Gustavo. El Derecho Dúctil: los caracteres generales del derecho constitucional actual. Madri: Trotta, 2007. 